\title{
ULTRA-HIGH MATERIAL-QUALITY SILICON PILLARS ON GLASS
}

\author{
Fude Liu, ${ }^{1}$ M.M. Al-Jassim, ${ }^{2}$ and D.L. Young ${ }^{2}$ \\ ${ }^{1}$ Department of Mechanical Engineering, The University of Hong Kong, Pokfulam Road, Hong Kong, China \\ 2 National Center for Photovoltaics, National Renewable Energy Laboratory, Golden, CO 80401, USA
}

\begin{abstract}
We investigated a unique crystalline silicon structure - silicon pillars - formed by melt crystallization using millisecond-long single-pulse pulses of $110-\mathrm{GHz}$ radiation of amorphous $\mathrm{Si}$ thin films deposited on glass by hot-wire chemical vapor deposition. With many microscopy techniques, we found that these pillars usually contain 1-4 randomly oriented grains with growth direction and grain boundaries perpendicular to the substrate surface. The grains in the Si pillars have ultra-high crystalline quality with grain sizes up to $20 \mathrm{~m}$. We attribute the formation mechanism of the $\mathrm{Si}$ pillars to the extremely high heating/cooling rates of $\mathrm{Si}$ on a glass substrate using millimeter-wave radiation and the important roles played by wetting and capping layers during the annealing process. Such understandings may enable us to prepare ultra-high-quality, large-grained poly-Si on inexpensive foreign substrates at large scale and low cost.
\end{abstract}

\section{INTRODUCTION}

There has recently been increased interest in polycrystalline silicon (poly-Si) (grain size: $1 \mu \mathrm{m} \sim 1 \mathrm{~mm}$ ) thin films on inexpensive substrates, especially for solar cells and high-mobility thin-film Si transistors [1-4]. Compared with hydrogenated amorphous silicon (a-Si:H) and microcrystalline silicon $(\mu \mathrm{c}-\mathrm{Si}: \mathrm{H})$ films, poly-Si thin films have many advantages such as better transport properties and no light-induced degradation effects $[5,6]$. However, it has been shown to be extremely challenging to grow high-quality poly-Si on inexpensive foreign substrates such as glass, metal-alloy tapes, and ceramics, with or without seed layer(s) [7-9]. Poly-Si films prepared by, for example, solid-phase crystallization of a-Si, contain either intolerantly high levels of intragrain defects or impurities not suitable for good device performance [10, 11]. In addition, inexpensive foreign substrates generally cannot be processed under high temperatures $\left(>600^{\circ} \mathrm{C}\right)$ for a long time in order to remove the defects. Moreover, the annealing condition may introduce more impurities from either the substrate or the ambient. To avoid these issues, it is necessary to expose the substrates to these elevated temperatures for very short periods of time. Because of its unique heating selectivity and short times, millimeter-wave pulse annealing is an ideal choice to meet these criteria.
In this work, we further investigate unique, threedimensional structures - silicon pillars-following our previous study. The pillars were formed by millisecond long, single-pulse annealing of $110-\mathrm{GHz}$ millimeter-wave radiation incident upon intrinsic amorphous silicon (a-Si) thin films deposited on glass by hot-wire chemical vapor deposition (HWCVD). The radiation annealing pulse melted the a-Si film and allowed crystallization into largegrain, egg-shaped pillars that are strongly adhered to the glass substrate. These pillars usually contain 1-4 randomly oriented grains with growth direction and grain boundaries perpendicular to the substrate surface. The grains in the Si pillars have ultra-high crystalline quality with grain sizes up to $20 \mu \mathrm{m}$.

\section{EXPERIMENTAL}

1-2 $\mu \mathrm{m}$ thick a-Si:H thin films were deposited onto glass substrates (Corning 1737) using HWCVD of silane gas. 1in. $\times 1$-in. glass substrates were coated with $\sim 120 \mathrm{~nm}$ of $\mathrm{SiO}_{2}$ by e-beam evaporation before deposition of the a$\mathrm{Si}: \mathrm{H}$. Samples were then placed in a tube furnace and annealed in flowing $\mathrm{N}_{2}$ for 90 minutes at $540^{\circ} \mathrm{C}$ to remove $\mathrm{H}$ from the a-Si, while not crystallizing the a-Si. Next, a $\sim 175$-nm-thick $\mathrm{SiO}_{2}$ capping layer was deposited over the a-Si by e-beam evaporation. The samples were then millimeter-wave annealed. Also, chemical etching was applied to reveal grain boundaries in the annealed samples.

Samples were studied systematically with many characterization methods. Field-emission scanning electron microscopy (FE-SEM) images were taken on a dual-beam focused ion beam (FIB) workstation (FEI-Nova 200 Dual Beam). Specifically selected sections crossing different $\mathrm{Si}$ pillars were prepared using this FIB workstation as well. These specimens were then investigated by cross-sectional transmission electron microscopy (TEM) (FEl-F20) at $200 \mathrm{kV}$. Grain orientation maps were done by electron backscatter diffraction (EBSD) with an SEM microscope (Hitachi S-4300N). More experimental details can be found elsewhere [12].

\section{RESULTS AND DISCUSSION}

The experimental setup of the millimeter-wave annealing is shown schematically in Figure 1. Samples were placed at the focal point of a millimeter-wave imaging setup within a vacuum chamber $\left(10^{-6}\right.$ torr). Samples were illuminated on an area of $1-\mathrm{cm} \times 1-\mathrm{cm}$ with $110-\mathrm{GHz}$ radiation single 
pulse from a 1-MW gyrotron. The power density at the sample was $\sim 40 \mathrm{~kW} / \mathrm{cm}^{2}$. Typical pulse lengths were 18.5 milliseconds in duration. During the short radiation pulse, the absorbed millimeter-wave energy is mainly due to the a-Si film absorption, which keeps the glass relatively cool. Our a-Si samples were easily melted $\left(\sim 1000-1450^{\circ} \mathrm{C}\right)$ with millisecond pulse lengths to form crystalline $\mathrm{Si}(\mathrm{c}-\mathrm{Si})$ structures, while not affecting the lowtemperature glass substrates.

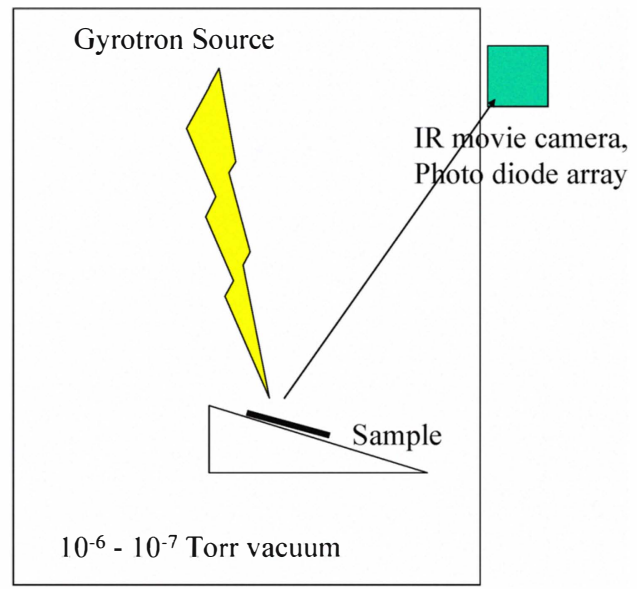

Fig. 1. Schematic of The experimental setup of the millimeter-wave annealing.

Fig. 2(a) shows schematically the initial structure of the a$\mathrm{Si}$ on $\mathrm{SiO}_{2}$ /glass samples before annealing. During the short single-pulse anneals by intense millimeter-wave radiation, the a-Si films melted (1000-1400 ${ }^{\circ} \mathrm{C}$ ) and formed c-Si. Fig. 2(b) shows the SEM image of a typical post-annealed $\mathrm{Si}$ film taken at a tilt angle of $52^{\circ}$. The melted a-Si film balled up on the glass substrate, and silicon pillars crystallized from the liquid melt. Most pillars appear to be bare silicon (uncovered), whereas others are coated with an unknown film (covered). The diameter and height of the pillars can be up to $20 \mu \mathrm{m}$.

In our previous study, EBSD was used to determine the orientation and number of grains in a particular pillar in an uncovered pillar region. Because the pillars were covered with a bi-layer of nc-Si and $\mathrm{SiO}_{2}$, we cut off the tips of the pillars with the FIB before carrying out EBSD mapping (Fig. 3(a)) to reveal the interior structure of the pillars. Using EBSD mapping on the tip-cut pillar, we determined the orientation of each grain in the pillar. The results indicated that most silicon pillars usually contain only 1-3 grains, which indicates that large grains can easily be achieved under such high-frequency, short-time millimeterwave annealing conditions. No preferential grain orientation was observed, which is similar to the case in SPC or $\mathrm{Cw}$ laser crystallization of a-Si, as well $[13,14]$. In addition, our results indicate that pillar growth occurred normal to the substrate. Because the aforementioned method is time consuming, we tried an easy approach to reveal the grains in a pillar. As shown in Fig. 3(b), grain boundaries can easily be seen under SEM imaging after chemical etching. To this particular pillar, there is only one grain boundary, i.e., the pillar contains two grains. The result is consistent with our previous results obtained with EBSD mapping [12]. (a)

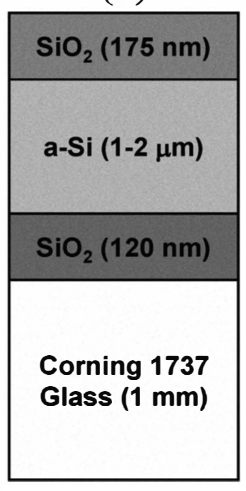

(b)

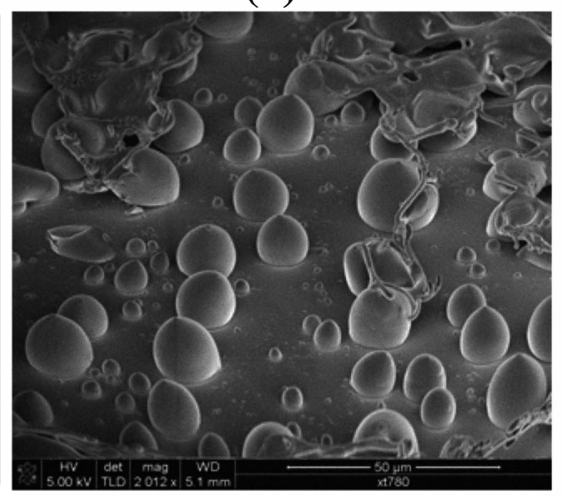

Fig. 2. (a) Schematic of the initial structure of the a-Si on $\mathrm{SiO}_{2} /$ glass samples before annealing. (b) SEM image of a typical post-annealed Si film taken at a tilt angle of $52^{\circ}$.

(a)
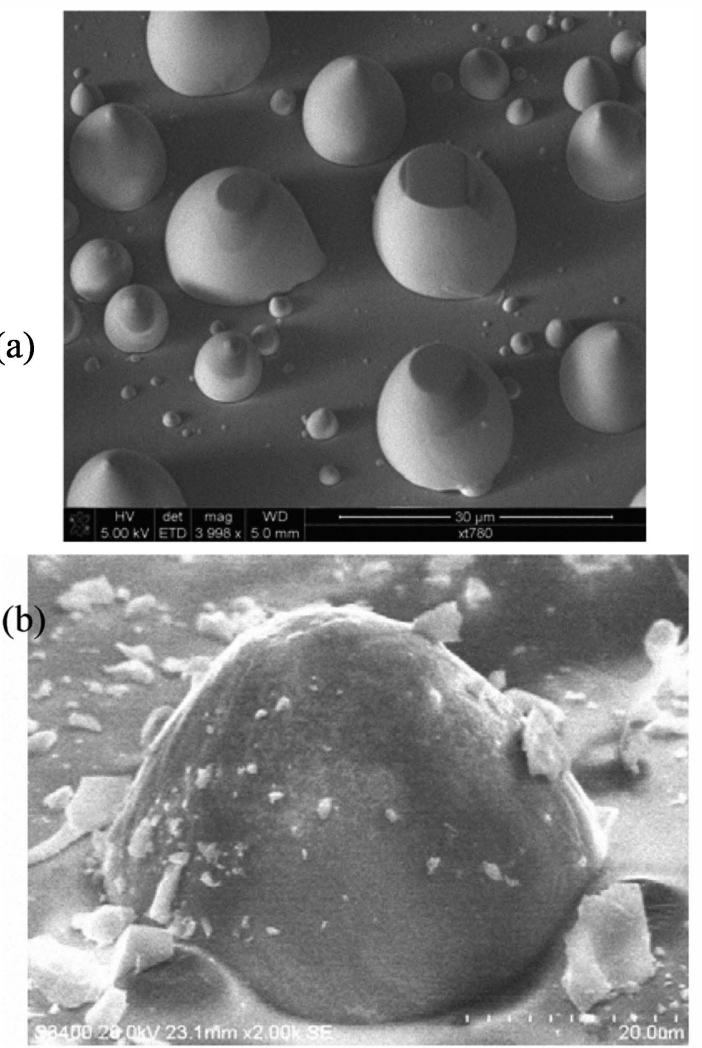

Fig. 3. (a) Uncovered pillars with their tips cut off by the FIB before carrying out EBSD mapping. (b) Grain boundary revealed under SEM imaging after chemical etching. 




(a)

Fig. 4. (a) Cross-sectional TEM image of a covered pillar.

Because it is not easy to cut the tips of pillars in the covered pillar regions, cross-sectional TEM specimens were prepared from specifically selected covered pillars using the FIB workstation. One such TEM specimen is shown in Fig. 4(a). The pillar happened to contain four grains. Similar to our previous results [12], the grain growth direction was observed to be perpendicular to the substrate surface and $\Sigma 3$ twins were mainly limited to the regions close to the Si/substrate interface. The Si pillar was covered by a thin $\mathrm{a}-\mathrm{SiO}_{2}(\sim 80 \mathrm{~nm})$ and a relatively thick nc-Si layer $(\sim 950 \mathrm{~nm})$ on the top and a thin $\mathrm{nc}-\mathrm{Si}$ layer $(\sim 120 \mathrm{~nm})$ and a thick $\mathrm{SiO}_{2}{ }^{*}$ layer (containing more defects) on the sides. More details on the structure, composition, and formation mechanism of the pillars were reported elsewhere [12]. EBSD mapping was carried on the same TEM specimen, and the results are shown in Fig. 4(b) (the image distortion was caused by sample drifting during mapping). The EBSD map (color-coated with inverse pole figure (IPF) coloring along the sample normal direction) further confirms that the pillar contained four grains. In addition, the grains are randomly oriented as in the case of uncovered pillars.

\section{CONLUSIONS}

Our results show that millisecond duration, millimeterwave, single-pulse annealing of intrinsic a-Si thin films deposited on glass with HWCVD produces very highquality crystalline silicon pillar structures firmly attached to the substrate. These pillars are usually composed of 1-4 crystalline silicon grains that are randomly oriented with a growth direction perpendicular to the substrate surface. The grains in the pillars are of ultra-high crystalline quality,



(b)

(b) EBSD map of the same TEM specimen.

with grain sizes up to $20 \mu \mathrm{m}$ wide and high. These highquality grains contain only $\Sigma 3$ twins, usually located close to the substrate. Our current findings are consistent with the previous results and further confirm the formation mechanism of Si pillars. We believe that such a capability will have a significant impact on developing highperformance Si-based devices such as solar cells and transistors.

\section{ACKNOWLEDGEMENT}

F. Liu thanks the financial support from Seed Funding Programme for Basic Research at HKU (Project Code 200910159016). At NREL, this work is supported by the U.S. Department of Energy under Contract No. DE-AC3608-G028308.

\section{REFERENCES}

[1] G. Beaucarne, Advances in OptoElectronics 2007, 2007, Article ID 36970.

[2] M. A. Green, Solar Energy 74, 2003, pp. 181-192.

[3] A. G. Aberle, Thin Solid Films 511-512, 2006, pp. 2634.

[4] A. Shah, P. Torres, R. Tscharner, N. Wyrsch, and H. Keppner, Science 285, 1999, pp. 692-698.

[5] D. L. Staebler and C. R. Wronski, Appl. Phys. Lett. 31, 1977, pp. 292-294. 
[6] R. E. I. Schropp, R. Carius, and G. Beaucarne, MRS Bulletin 32, 2007, pp. 219-222.

[7] A. G. Aberle, J. Cryst. Growth 287, 2006, pp. 386390.

[8] I. Gordon, D. V. Gestel, K. V. Nieuwenhuysen, L. Carnel, G. Beaucarne, and J. Poortmans, Thin Solid Films 487, 2005, pp. 113-117.

[9] C. W. Teplin, D. S. Ginley, and H. M. Branz, J. NonCryst. Solids 352, 2006, pp. 984-988.

[10] F. Liu, M. J. Romero, K. M. Jones, A. G. Norman, M. M. Al-Jassim, D. Inns, and A. G. Aberle, Thin Solid Films 516, 2008, pp. 6409-6412.
[11] M. L. Terry, A. Straub, D. Inns, D. Song, and A. G. Aberle, Appl. Phys. Lett. 86, 2005, pp. 172108.

[12] F. Liu, K. M. Jones, Y. Xu, W. Nemeth, J. Lohr, J. Neilson, M. J. Romero, M. M. Al-Jassim, and D. L. Young, Adv. Mater. 21, 2009, pp. 3002-3006.

[13] D. L. Young, P. Stradins, E. Iwaniczko, B. To, B. Reedy, Y. Yan, H. M. Branz, J. Lohr, M. Alvarez, J. Booske, A. Marconnet, and Q. Wang, Mater. Res. Soc. Symp. Proc. 862, 2005, pp. A10.5.1-A10.5.6.

[14] P. Stradins, D. Young, H. M. Branz, M. Page, and Q. Wang, Mater. Res. Soc. Symp. Proc. 862, 2005, pp. A16.1.1-A16.1.6. 